\title{
Cardiac herniation after blunt thoracic trauma
}

\author{
Jonathon Broughton MD, Duncan Maguire MD, Nicholas LeBlanc MD
}

- Cite as: CMAJ 2020 April 27;192:E454. doi: 10.1503/cmaj.191446

A 24-year-old man was brought by ambulance to a rural hospital after a motor vehicle collision. On physical examination, he was hemodynamically unstable with a blood pressure of $60 / 40 \mathrm{~mm} \mathrm{Hg}$ and a heart rate of $120 \mathrm{bpm}$. He had unequal upper-extremity blood pressures, muffled heart sounds and a left-sided flail chest. The patient required intubation, bilateral chest tubes and multiple blood transfusions. Pointof-care echocardiography was attempted, but the heart was not visualized owing to air artifacts and an abnormal anatomic position.

Initial radiography of the chest showed a left-sided flail segment and dextrocardia (Figure 1A). Computed tomography confirmed cardiac herniation into the right hemithorax, with associated torsion and narrowing of the right main pulmonary artery and constriction of the pulmonary veins (a video [Appendix 1] is available at www.cmaj. ca/lookup/suppl/doi:10.1503/cmaj.191446/-/DC1).

The patient was flown in unstable condition to the nearest trauma centre and required ongoing aggressive resuscitation. On arrival, he underwent emergent bilateral thoracosternotomy to reduce the herniation and repair the pericardium (Figure 1B). He had a prolonged course in the intensive care unit secondary to difficulties with ventilation but eventually made a full recovery and was discharged home.

Pericardial rupture is uncommon, occurring in less than $0.5 \%$ of cases of blunt trauma. ${ }^{1}$ In cases of right-sided pericardial rupture, the heart can herniate into the right thorax with associated torsion of great vessels, ${ }^{1}$ which is associated with high mortality rates in patients who survive to hospital. ${ }^{2}$ Findings from chest radiography in patients with substantial thoracic trauma that should raise clinical suspicion of cardiac herniation include pneumopericardium, pneumomediastinum, a prominent cardiac silhouette or new dextrocardia. ${ }^{2}$ Emergency consultation with thoracic or cardiac surgery is essential for definitive management of this condition, because surgical intervention is essential to restore hemodynamic stability. ${ }^{3}$ In the event of ongoing instability or cardiac arrest, resuscitative thoracotomy to detort the herniation should be considered by any physician trained in the technique.

\section{References}

1. Chughtai T, Chiavaras MM, Sharkey $P$, et al. Pericardial rupture with cardiac herniation. Can J Surg 2008;51:E101-2.

2. Sherren PB, Galloway R, Healy M. Blunt traumatic pericardial rupture and cardiac herniation with a penetrating twist: two case reports. Scand J Trauma Resusc Emerg Med 2009;17:64.

3. Janson JT, Harris DG, Pretorius J, et al. Pericardial rupture and cardiac herniation after blunt chest trauma. Ann Thorac Surg 2003;75:581-2.

\section{Competing interests: None declared.}

This article has been peer reviewed.

The authors have obtained patient consent.

Affiliations: Departments of Emergency Medicine (Broughton), Anesthesia (Maguire) and Thoracic Surgery (LeBlanc), Rady College of Medicine, University of Manitoba, Winnipeg, Man.

Acknowledgement: The authors would like to thank the large multidisciplinary team who came together to help achieve this patient's successful outcome.

Correspondence to: Jonathon Broughton, umbrougj@myumanitoba.ca

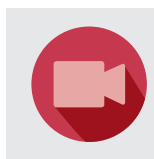
A video of cardiac herniation after blunt thoracic trauma in a 24-year-old man is available in Appendix 1, at www. cmaj.ca/lookup/suppl/doi:10.1503/cmaj.191446/-/DC1 